\title{
Registration System for Growth Hormone (GH) Treatment with Standardized Immunoreactive GH Values in Japan
}

\author{
TOSHIAKI TANAKA, KAZUE TAKANO, KUNIHIKo HANEW, YosHIKAZU NISHI, YUTAKA IGARASHI, \\ TAKEKI HIRANO, TOMOHIRo SAITO, KATSUHIKo TACHIBANA, SUSUMU YOKOYA, KENJI FUJIEDA, \\ AKIRA SHIMATSU, NAOMI HIZUKA, TOSHIO TSUSHIMA, AND MINORU IRIE
}

GH and its Related Factors Study Committee \& GH Treatment Study Committee; The Foundation for Growth Science, Japan

\begin{abstract}
The Foundation for Growth Science has been controlling the use of GH by its registration system, which includes a scoring system for the eligibility for GH treatment according to the diagnostic criteria for GH deficiency (GHD) established by the Study Group for Hypothalamo-pituitary Disorder of the Ministry of Health and Welfare. Until 1995, 28,876 patients with GHD (19,432 boys and 9,444 girls) had been registered as eligible for $\mathrm{GH}$ treatment. The number of patients registered in a year increased gradually till 1990 due to the unlimited hGH supply by recombinant techniques and the change in the criteria for $\mathrm{GH}$ treatment and the number registered became stable after 1990 . The frequency of GHtreated patients is calculated to be $55.2 / 100,000$ persons $(72.2 / 100,000$ in boys and $37.1 / 100,000$ in girls) in patients born between 1960 and 1990 . The highest frequency was $148.4 / 100,000$ persons (191.7/ 100,000 boys and $103.7 / 100,000$ girls) in 1981 , when 2,278 patients (1,508 boys and 770 girls) were born. Eligibility for GH treatment is assessed according to the scoring system which is basically dependent on peak $\mathrm{GH}$ values in provocation tests so that standardization of $\mathrm{GH}$ values measured with the various commercial GH kits is required to avoid inequality of patients' access to the treatment. In samples obtained by GRF test in 10 normal volunteers, hGH was measured with seven human GH (hGH) kits at a laboratory center. Since the RIA value has been used historically for the diagnosis of GHD, the mean of two RIA measurements was selected as the basis for the standardization procedure and the linear regression formula was used for each hGH kit. After the freely available supply of hGH obtained by recombinant DNA techniques, the role of the Foundation for Growth Science has changed to avoid hGH abuse. Even with this regulation, the frequency of registered patients may indicate a tendency to $\mathrm{GH}$ overuse.
\end{abstract}

Key words: GH treatment, Registration system, GH measurement, Frequency of GHD

(Endocrine Journal 45: 459-465, 1998)

IN 1995, the Drug and Therapeutics Committee of the Lawson Wilkins Pediatric Endocrine Society published "Guidelines for the use of $\mathrm{GH}$ in children with short stature"[1], in which they state the difficulty of diagnosis in short children with subtle abnormalities of $\mathrm{GH}$ secretion and recommend a trial of $\mathrm{GH}$ therapy in subtler forms of $\mathrm{GH}$

Received: November 27, 1997

Accepted: February 17, 1998

Correspondence to: Dr. Toshiaki TANAKA, Department of Endocrinology \& Metabolism, National Children's Hospital, 3-35-31 Taishido, Setagaya-ku, Tokyo 154, Japan deficiency with careful monitoring of its effectiveness. They also emphasize the importance for establishing a centralized system for the use of $\mathrm{GH}$ including reporting, evaluating, and disseminating information on potential adverse events of GH treatment.

In Japan, the Foundation for Growth Science has been controlling the use of $\mathrm{GH}$ for some years by its registration system, which includes criteria for $\mathrm{GH}$ treatment, a trial in subtler forms of GH deficiency and a system for reporting adverse events. In this article we introduce the registration system for GH treatment in Japan. We also report 
the method of standardization of $\mathrm{GH}$ values measured with different commercial kits for evaluation of eligibility for $\mathrm{GH}$ treatment.

\section{Subjects and Methods}

\section{Registration system for GH treatment}

Physicians who want to treat short children with $\mathrm{GH}$ are required to apply for judgement of eligibility. When the patient is judged as eligible for $\mathrm{GH}$ treatment, the Foundation registers the patient and issues the authorization for $\mathrm{GH}$ treatment. The physician is required to report the effect of the $\mathrm{GH}$ treatment every year and the foundation judges eligibility for continuation of $\mathrm{GH}$ treatment according to the $\mathrm{GH}$ effect. Authorization for the continuation of $\mathrm{GH}$ treatment is issued every year. A Grant from the local governments is renewed every year, when the new authorization by the Foundation is also required for a Grant application by most local governments.

\section{Criteria for GH treatment (Table 1 and Fig. 1)}

The diagnostic criteria for GH deficiency (GHD) were established by the Study Group for Hypothalamo-pituitary Disorder of the Ministry of Health and Welfare. The GH Treatment Committee in the Foundation for Growth Science prepared the scoring system to judge the eligibility for $\mathrm{GH}$ treatment according to these diagnostic criteria established by the Study Group.

The premise condition consists of auxological data such as bone age, height SD score (SDS) and growth velocity SDS. Since infants with symptomatic hypoglycemia, probably caused by GH deficiency, should be treated promptly, they are included regardless of height SDS or growth velocity SDS.

The next step is Criterion I (Table 1); the results of provocation tests are scored according to the peak $\mathrm{GH}$ values. When the sum of points in provocation tests is equal to or more than 6 points, the patient is judged as eligible for $\mathrm{GH}$ treatment for one year. When the sum of the points according to Criterion I does not reach 6 points, the patient can be further evaluated according to Criterion II (Table 1). When the sum of points according to
Criterion II is equal to or more than 6 points, the patient is judged as eligible for $\mathrm{GH}$ treatment for one year. A patient who is judged as not eligible according to Criterion I or II, the patient is judged as eligible for a 6 month-trial or as not eligible according to the points according to Criterion I and II, as shown Fig. 1.

Doctors treating GHD patients with GH have to report the effect of the treatment every year except after 6 months in a 6-month trial. Continuation of GH treatment is judged according to the criteria for the continuation of $\mathrm{GH}$ treatment shown in Table 2. When growth velocity in patients treated with $\mathrm{GH}$ fulfill the criteria for continuation of $\mathrm{GH}$ treatment shown in Table 2, authorization for the continuation of GH treatment is issued. When patients treated with GH fulfill the criteria for the recommendation to stop $\mathrm{GH}$ treatment shown in Table 3, the recommendation to stop GH treatment is issued.

When doctors are not satisfied with the judgement of eligibility for GH treatment or the recommendation to stop treatment, they can lodge a claim with the GH Treatment Committee. Judgement of the claim is made by a majority decision of the Committee members.

\section{Standardization of $G H$ values}

Eligibility for $\mathrm{GH}$ treatment is assessed according to the scoring system which is basically depending on peak $\mathrm{GH}$ values in provocation tests. Therefore, correction of discrepancies among $\mathrm{GH}$ values measured with the various commercial GH kits is required to avoid inequality of patients' access to the treatment.

RIA kits were obtained from Eiken Chemical Co., Ltd., and Dainabot Co., Ltd., IRMA kits were obtained from Eiken Chemical Co., Ltd., Pharmacia K. K., and Daiichi Radioisotope Labs, Ltd. The IEMA (immunoenzymometric assay) kit was obtained from Tosoh Co., Ltd. and CLEIA (chemiluminescent enzyme immunoassay) kit from Hitachi Kasei Co., Ltd. GHRH test was performed in ten healthy adult volunteers, aged 18 to $47 \mathrm{yr}$ and 60 serum samples was kept at $-20^{\circ} \mathrm{C}$ until measurement.

In each sample, hGH was measured with seven hGH kits at a laboratory center. Since the cut-off values were $5,7.5,10$ and $15 \mathrm{ng} / \mathrm{ml}$ for Criterion I 
Table 1. Criteria for hGH treatment issued by the Foundation for Growth Science (revised in 1997)

Candidates for hGH treatment must fulfill the following A and B, or C before assessment according to Criteria I and II.

A. Bone age: $<17$ years for boys $<15$ years for girls

B. Height SD score: $\leq-2.0 \mathrm{SD}$

or

Growth velocity SD score: $\leq-1.5 \mathrm{SD}$ for chronological age during preceding two years

(boys < 11 years; girls $<9$ years)

$\leq-1.5 \mathrm{SD}$ for bone age during preceding two years

(boys $\geq 11$ years; girls $\geq 9$ years)

C. Symptomatic hypoglycemia in infants, probably caused by GH deficiency

Criterion I, Provocation tests (more than two)

1) Peak GH: Arginine, glucagon, L-dopa, clonidine or insulin test $\leq 5.0 \mathrm{ng} / \mathrm{ml} \rightarrow 4$ points, 5.0 to $\leq 10.0 \mathrm{ng} / \mathrm{ml} \rightarrow 3$ poitns, $>10.0 \mathrm{ng} / \mathrm{ml} \rightarrow 0$ points

2) Peak GH: Glucagon-propranolol, insulin-propranolol or GHRH test $\leq 7.5 \mathrm{ng} / \mathrm{ml} \rightarrow 4$ points, 7.5 to $\leq 15.0 \mathrm{ng} / \mathrm{ml} \rightarrow 3$ points, $>15.0 \mathrm{ng} / \mathrm{ml} \rightarrow 0$ points

Criterion II

1) Past history of breech delivery, asphyxia, severe or prolonged jaundice, cranial radiation, organic brain disease or abnormal findings at pituitary or hypothalamus by imaging 2 points

2) Mean plasma (serum) GH during 3-h nocturnal sleep ( 8 times or more, every $20 \mathrm{~min}$ ) $\leq 4.0 \mathrm{ng} / \mathrm{ml} \rightarrow 3$ points, 4.0 to $\leq 5.0$ $\mathrm{ng} / \mathrm{ml} \rightarrow 2$ points, $>5.0 \mathrm{ng} / \mathrm{ml} \rightarrow 0$ point

or

Urinary hGH concentration (nocturnal urine or 24-h urine)

$\leq 5.0 \mathrm{pg} / \mathrm{mgCr} \rightarrow 1$ point, 5.0 to $\leq 7.0 \mathrm{pg} / \mathrm{mgCr} \rightarrow 0.5 \mathrm{point},>7.0 \mathrm{pg} / \mathrm{mgCr} \rightarrow 0$ point

The points by frequent urinary measurement can be added till upper limit of 2 points is reached.

The points by mean plasma (serum) GH during 3-h nocturnal sleep and by urinary hGH measurement cannot be added.

3) Plasma (serum) IGF-I

Chronological age $<7$ years;

$\leq 40 \mathrm{ng} / \mathrm{ml} \rightarrow 2$ points, 40 to $\leq 55 \mathrm{ng} / \mathrm{ml} \rightarrow 1$ point, $>55 \mathrm{ng} / \mathrm{ml} \rightarrow 0$ point

Chronological age $7 \leq$ to $<11$ years;

$\leq 80 \mathrm{ng} / \mathrm{ml} \rightarrow 2$ points, 80 to $\leq 120 \mathrm{ng} / \mathrm{ml} \rightarrow 1$ point, $>120 \mathrm{ng} / \mathrm{ml} \rightarrow 0$ point

Chronological age $\geq 11$ years;

$\leq 100 \mathrm{ng} / \mathrm{ml} \rightarrow 2$ points, 100 to $\leq 150 \mathrm{ng} / \mathrm{ml} \rightarrow 1$ point, $>150 \mathrm{ng} / \mathrm{ml} \rightarrow 0$ point or

Serum IGFBP-3

Chronological age $<7$ years;

$\leq 1.0 \mu \mathrm{g} / \mathrm{ml} \rightarrow 2$ points, 1.0 to $\leq 1.5 \mu \mathrm{g} / \mathrm{ml} \rightarrow 1$ point, $>1.5 \mu \mathrm{g} / \mathrm{ml} \rightarrow 0$ point

Chronological age $7 \leq$ to $<11$ years;

$\leq 1.5 \mu \mathrm{g} / \mathrm{ml} \rightarrow 2$ points, 1.5 to $\leq 2.0 \mu \mathrm{g} / \mathrm{ml} \rightarrow 1$ point, $>2.0 \mu \mathrm{g} / \mathrm{ml} \rightarrow 0$ point

Chronological age $\geq 11$ years;

$\leq 2.0 \mu \mathrm{g} / \mathrm{ml} \rightarrow 2$ points, 2.0 to $\leq 2.5 \mu \mathrm{g} / \mathrm{ml} \rightarrow 1$ point, $>2.5 \mu \mathrm{g} / \mathrm{ml} \rightarrow 0$ point

The points by plasma (serum) IGF-I and serum IGFBP-3 cannot be added.

4) (Bone age/Chronological age) $\times 100 \leq 80$ 2 points

D. Final judgement for hGH treatment

1. Suitable for one year: $\geq 6$ points either in criterion I or II

2. 6-month trial: from 3 to 5 poitns in criterion I and from 2.5 to 5.5 points in criterion II

3. Not suitable: (1) Neither A nor B fulfiled

(2) Neither D-1 nor D-2 fulfilled

(Table 2), 51 samples with hGH values between 2 $\mathrm{ng} / \mathrm{ml}$ and $25 \mathrm{ng} / \mathrm{ml}$ obtained by two RIA measurements were selected as the basis for the correction procedure. The mean of two RIA measurements (Daiichi RIA and Eiken RIA) was defined as the standard hGH value of the sample, since historically RIA was the first to be introduced for the diagnosis of GHD. The linear regression formula for the $\mathrm{GH}$ value obtained with each kit and the mean of two RIA measurements was calculated. 


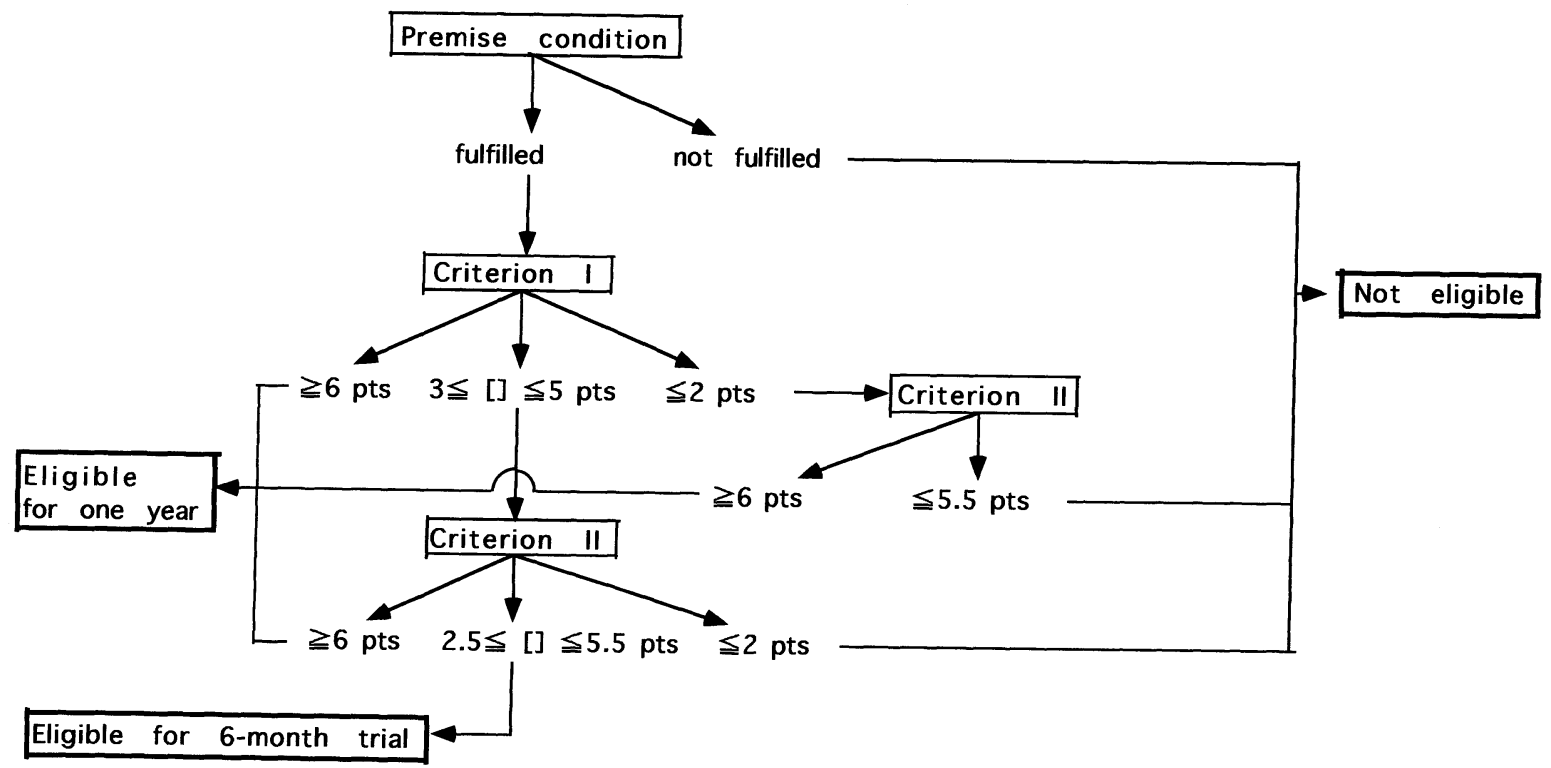

Fig. 1. Flow chart to judge the eligibility for $\mathrm{GH}$ treatment. pts, points.

Table 2. Criteria for continuation of $\mathrm{GH}$ treatment

The patients must fulfill the following three.

1. Growth velocity in a year fulfills any of following three.

a) Growth velocity $\geq 6 \mathrm{~cm} /$ year

b) Increase in growth velocity in the first year $\geq 2 \mathrm{~cm} /$ year

c) Growth velocity in the second treatment year $\geq 2.0 \mathrm{~cm} /$ year

Growth velocity in the third treatment year $\geq 2.0 \mathrm{~cm} /$ year

Growth velocity in the fourth treatment year $\geq 1.8 \mathrm{~cm} /$ year

Growth velocity in the fifth treatment year $\geq 1.4 \mathrm{~cm} /$ year

Growth velocity in the sixth treatment year $\geq 1.2 \mathrm{~cm} /$ year

Growth velocity in the greater than seventh treatment year $\geq 1.0 \mathrm{~cm} /$ year

2. Bone age $<17$ years in boys or $<15$ years in girls

3. No severe adverse events

Table 3. Criteria for recommendation to stop GH treatment

When the patients fulfill one of the following three:

1. Growth velocity $<1.0 \mathrm{~cm} /$ year

2. Bone age $\geq 17$ years in boys and $\geq 15$ years in girls

3 . Severe adverse events

\section{Results}

Until 1995, 28,876 patients with GHD (19,432 boys and 9,444 girls) had been registered as eligible for $\mathrm{GH}$ treatment. Figure 2 shows the number of registered patients according to the year registered. The number of patients registered in a year increased gradually till 1990 due to the unlimited supply of hGH obtained by recombinant techniques, and the change in the criteria for $\mathrm{GH}$ treatment and the registered number became stable after 1990. The ratio of boys to girls is approximately 2 to 1 .

The frequency of GH-treated patients was calculated by the formula (number of patients/total birth number in general population) and the results are shown in Fig. 3. The frequencies were 55.2/ 100,000 persons $(72.2 / 100,000$ boys and $37.1 /$ 100,000 girls) from 1960 till 1990 and 119.5/100,000 persons (155.5/100,000 boys and 81.6/100,000 girls) from 1976 till 1985. The highest frequency was $148.4 / 100,000$ persons $(191.7 / 100,000$ boys and 


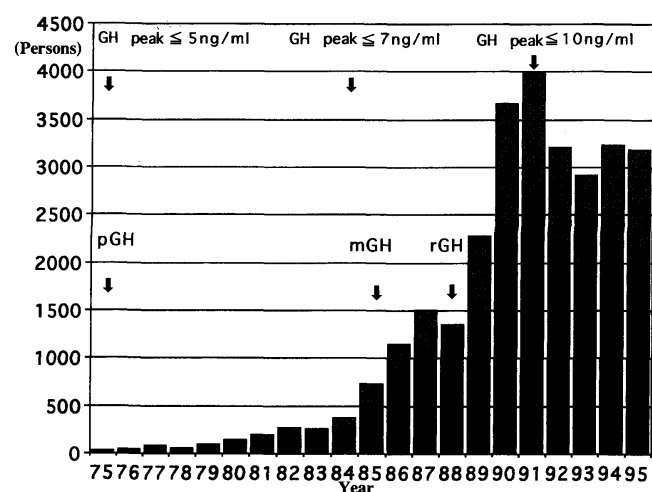

Fig. 2. GHD number registered at the Foundation for Growth Science.

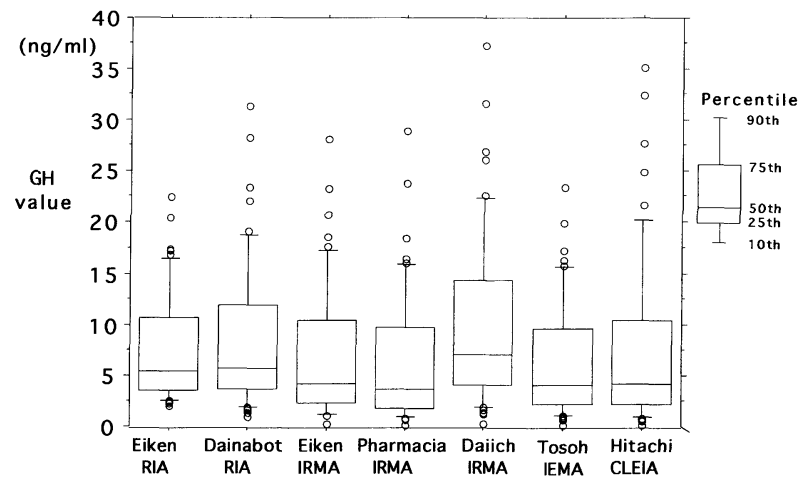

Fig. 4. GH value measured with seven hGH kits.

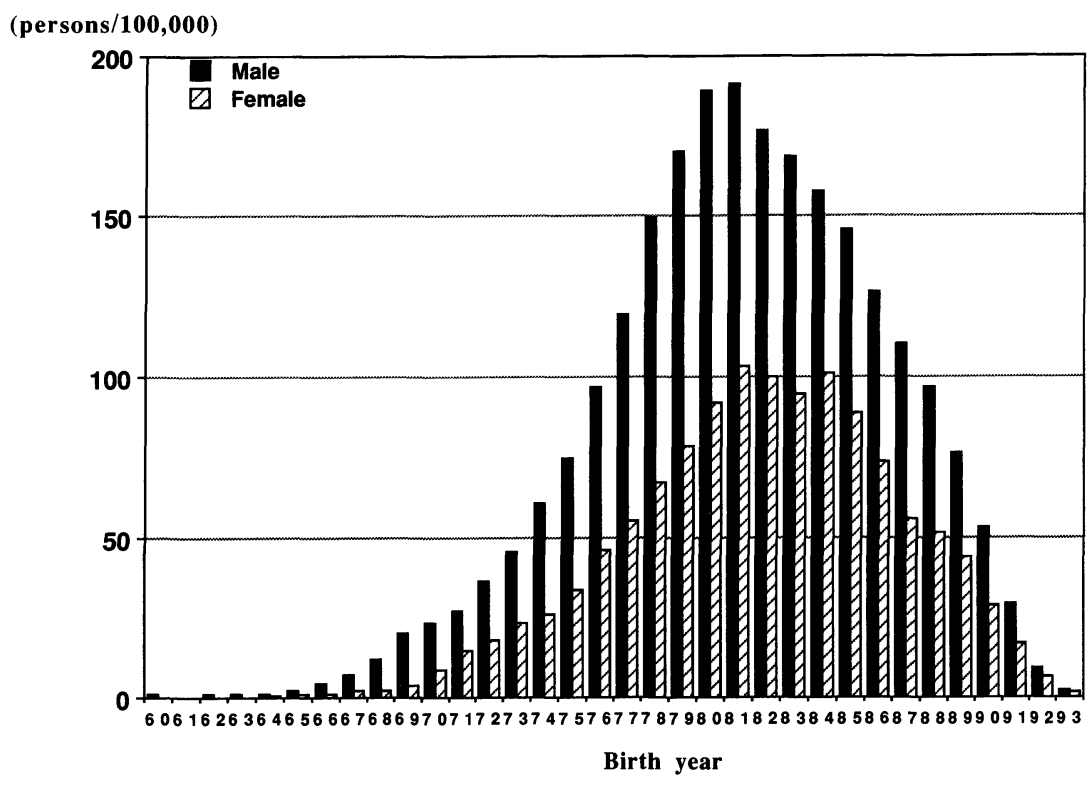

Fig. 3. Frequency of GHD according to birth year.

$103.7 / 100,000$ girls) in 1981 , when 2,278 patients ( 1,508 boys and 770 girls) were born.

Figure 4 shows the $\mathrm{GH}$ values measured by the seven hGH kits using serum samples obtained from healthy subjects on GHRH test. Pharmacia IRMA gave the lowest values and Daiichi IRMA the highest values on average. Table 4 shows a linear regression formula for each measurement to adjust the measured value to the standard value, which is the mean of two RIA measurements (Daiichi RIA and Eiken RIA). All the hGH values were used for the judgement of eligibility for GH treatment only after standardization by means of a linear regression formula.
Table 4. Linear regression and correlation coefficient against the mean of RIA kits

\begin{tabular}{lcc}
\hline Assay kit & $\mathrm{Y}=($ Eiken RIA+Dainabot RIA $) / 2$ & $\mathrm{r}$ \\
\hline Eiken RIA & $1.18 \mathrm{X}-0.92$ & 0.995 \\
Dainabot RIA & $0.86 \mathrm{X}+0.73$ & 0.998 \\
Eiken IRMA & $0.93 \mathrm{X}+1.42$ & 0.952 \\
Pharmacia IRMA & $0.97 \mathrm{X}+1.89$ & 0.970 \\
Daiichi IRMA & $0.72 \mathrm{X}+0.83$ & 0.991 \\
Tosoh IEMA & $1.10 \mathrm{X}+0.97$ & 0.993 \\
Hitachi-Kasei CLEIA & $0.72 \mathrm{X}+2.64$ & 0.915 \\
\hline
\end{tabular}




\section{Discussion}

In Japan, $\mathrm{GH}$ treatment for $\mathrm{GH}$ deficient children was initiated in 1975, but because no domestic pharmaceutical companies in Japan have produced $\mathrm{hGH}$, all the hGH products for clinical use have been imported since then. Because of the shortage of pituitary-derived hGH, the Foundation for Growth Science was founded in 1977 to collect pituitary glands in our own country for hGH preparation and to deliver $\mathrm{hGH}$ to registered patients with GHD after judgement of eligibility for $\mathrm{GH}$ treatment. The registration system has been continued even after the unlimited supply of hGH obtained by recombinant DNA techniques, since regulation to avoid overuse of hGH has been required by the Ministry mainly for financial reasons. Therefore, the role of the Foundation for Growth Science has now changed to avoid hGH abuse and to keep the medical expense.

$\mathrm{GH}$ is very expensive in Japan: a $4 \mathrm{U}$-vial costs approximately $\$ 200$ which is 2 or 3 times more expensive than in the other countries. GH-deficient patients cannot afford treatment with $\mathrm{GH}$ without sufficient financial support. That is why $70 \%$ of the medical expense for hGH treatment is covered by social insurance and the rest is covered by a Grant for Special Chronic Children's Disease supported by the Ministry of Health and Welfare and by local governments. Authorization by the Foundation for Growth Science is required to apply for a grant from many local governments, so that the registration system is still working effectively. Most physicians agree with the need for this regulation.

Even with this regulation, the numbers of patients has increased significantly. The number of the children with short stature (below $-2 \mathrm{SD}$ ) is expected to be $2,275 / 100,000$ persons according to the statistical definition. The highest frequencies of GH-treated patients were 191.7/100,000 boys and $103.7 / 100,000$ girls born in 1981. This indicated that $8.4 \%$ of short boys and $4.6 \%$ of short girls were treated with GH. Ogawa et al. [2] conducted a screening program for GHD in the Okazaki area. Among 27,936 children who had a regular health check at 1.5 years or 3 years at local health centers, 662 short children (below - 2 SD) were followed up till 4 or 5 years of age. GH secretion capacity was evaluated in 79 short children, and 23 children were diagnosed as having GHD. Therefore, the frequency of GHD was calculated as $3.4 \%$ of short children. The frequency in registered patients born in 1981 was significantly higher than that in an area based study by Ogawa et al. [2]. This may indicate a tendency to GH overuse. It is highly probable that the number of GH-treated short children will increase without this regulation by the Foundation, since many short children visit outpatient clinics of pediatric endocrinologists. $\mathrm{GH}$ treatment has not been established in terms of normalization of final height [3]. The Foundation has to evaluate $\mathrm{GH}$ treatment who should be treated (reevaluation of Criteria) and how they should be treated by analysing the data base in the Foundation.

An application form for eligibility for $\mathrm{GH}$ treatment contains not only height, bone age, and laboratory data such as peak $\mathrm{GH}$ values, levels of IGF-I, IGFBP-3, thyroid hormone (to exclude hypothyroidism) and urinary $\mathrm{GH}$, but also parents' height, gestational age, birth weight, birth length, delivery presentation, severity of jaundice, etc. The annual report of the $\mathrm{GH}$ effectiveness by the physician contains the height and weight of the patients, GH dose, additional therapy and adverse events. Therefore, these data can be used for the scientific analysis of $\mathrm{GH}$ treatment. The GH Treatment Study Committee have published several reports using this database of the Foundation [36]. Adverse events has also been collected and analysed.

In Japan seven measurement kits are commercially available. As it is well known that $\mathrm{GH}$ concentrations vary according to the assay method [7-11], we have standardized the GH values measured with these commercial kits. The study described here was performed in 1996. This standardization has been in use since 1991 and standardization formulas are revised every year by the same method. In addition, GH and its Related Factors Study Committee in the Foundation for Growth Science receives quality control data for every GH kit and IGF-I kit from manufacturers every month. As a result of these efforts, the scoring system of the Foundation for Growth Science is approved by most of the physicians treating GHD with GH. 


\section{References}

1. Guidelines for the use of growth hormone in children with short stature (1995) A report by the Drug and Therapeutic Committee of the Lawson Wilkins Pediatric Endocrine Society. J Pediatr 127: 857-867.

2. Ogawa M, Yazawa T, Mori S (1992) Study on screening program for GHD. Report of the Study Group for Hypothalamo-pituitary Disorder of the Ministry of Health and Welfare, 291-293 (In Japanese).

3. Takano K, Tanaka T, Saito T (1994) Quality of life of growth hormone treated adults. Clin Pediatr Endocrinol 3 (Suppl 4): 47-53.

4. Takano K, Shizume K, Hibi I, Ogawa Y, Suwa S, Tanaka T (1993) Growth hormone treatment in Turner syndrome: Results of a multicentre study in Japan. Horm Res 39 (Suppl 2): 37-41.

5. Tanaka T, Takano K, Hanew K, Nishi Y, Fujieda K, Tachibana K, Yokoya S, Igarashi Y, Hirano T (1996) Spontaneous growth in growth hormone-treated short children. Endocr J 43 (Suppl): S135-S136.

6. Fujieda K, Hanew K, Hirano T, Igarashi Y, Nishi Y, Tachibana K, Takano K, Tanaka T, Yokoya S (1996) Growth responses to growth hormone therapy in patients with different degree of growth hormone deficiency. Endocr J 43 (Suppl): S19-S25.

7. Reiter EO, Morris AH, MacGillivray MH, Weber D (1988) Variable estimates of serum growth hormone concentrations by different radioassay systems. $J$ Clin Endocrinol Metab 66: 68-71.

8. Blethen S, Chasalow F (1983) Use of a two-site immunoradiometric assay for growth hormone in identifying children with GH-dependent growth failure. J Clin Endocrinol Metab 57: 1031-1037.

9. Celnicker AC, Chen AB, Wert RBM, Sherman BM (1990) Variability of quantitation of circulating growth hormone using commercial immunoassays. J Clin Endocrinol Metab 68: 469-476.

10. Chatelain P, Bouillat B, Cohen R, Sassolas G, Souberbielle JC, Ruitton A, Joly MO, Job JC (1990) Assay of growth hormone levels in human plasma using commercial kits: Analysis of some factors influencing the results. Acta Paediatr Scand 370 (Suppl): 56-61.

11. Albertsson-Wikland K, Jansson C, Rosberg S, Novamo A (1993) Time-resolved immunofluorometric assay of human growth hormone. Clin Chem 39: 1620-1625. 